Research Article

\title{
Prediction of Residual Gas Content during Coal Roadway Tunneling Based on Drilling Cuttings Indices and BA-ELM Algorithm
}

\author{
Zhenhua Yang $\mathbb{B}$, Hongwei Zhang, Sheng Li, and Chaojun Fan \\ College of Mining, Liaoning Technical University, Fuxin, Liaoning, China \\ Correspondence should be addressed to Zhenhua Yang; 1904835575@qq.com
}

Received 14 August 2019; Accepted 1 April 2020; Published 24 April 2020

Academic Editor: Hossein Moayedi

Copyright ( ) 2020 Zhenhua Yang et al. This is an open access article distributed under the Creative Commons Attribution License, which permits unrestricted use, distribution, and reproduction in any medium, provided the original work is properly cited.

\begin{abstract}
In order to predict the residual gas content in coal seam in front of roadway advancing face accurately and rapidly, an improved prediction method based on both drilling cuttings indices and bat algorithm optimizing extreme learning machine (BA-ELM) was proposed. The test indices of outburst prevention measures (drilling cuttings indices, residual gas content in coal seam) during roadway advancing in Yuecheng coal mine were first analyzed. Then, the correlation between drilling cuttings indices and residual gas content was established, as well as the neural network prediction model based on BA-ELM. Finally, the prediction result of the proposed method was compared with that of back-propagation (BP), support vector machine (SVM), and extreme learning machine (ELM) to verify the accuracy. The results show that the average absolute error, the average absolute percentage error, and the determination coefficient of the proposed prediction method of residual gas content in coal seam are $0.069,0.012$, and 0.981 , respectively. This method has higher accuracy than other methods and can effectively reveal the nonlinear relationship between drilling cuttings indices and residual gas content. It has prospective application in the prediction of residual gas content in coal seam.
\end{abstract}

\section{Introduction}

Coal and gas outburst, a kind of mine dynamic disasters, are characterized by the sudden ejection of large masses of coals or volumes of gases in a short time. Gas outbursts destroy the mining space and cause damage to production equipment, thus imposing serious threat to the safety of workers during underground coal mining. With depletion of shallow coal resources, the mining depth of coal mines in China increases. The coupling effect of great in situ stress and high gas pressure in deep coal seam increases the risk of gas outbursts [1-5].

The residual gas content is an important parameter for gas outburst prediction. It is of significance to determine the residual gas content ahead of advancing face quickly and accurately and to provide scientific guidance for roadway tunneling [6-9]. At present, the investigations into the gas content prediction by different scholars can be divided into two categories. First, theoretical analyses of the geological factors affecting the gas existence in coal seam, such as the burial depth, inclination angle of coal seam, lithology of roof and floor, and geological structure of mine field, were carried out [10-14]. Second, the grey theory, artificial neural network, and other machine learning algorithms were applied to predict coal seam gas content. The prediction method is determined through the comparative analysis of prediction results [15-17]. The above static-factor-based methods for the residual gas content prediction have achieved good results in the field application. However, these prediction methods have limitations due to the complex and dynamic geological conditions and material properties of coal seams.

Some methods have been proposed to predict the residual gas content in coal seam ahead of roadway advancing face after gas predrainage. The indices used for risk prediction of gas outbursts include gas desorption index $\left(K_{1}\right)$ and weight of drilling cuttings $(S)$. Based on the laboratory 
test of gas desorption, Zhang et al. [18] proposed a method for the rapid determination of residual gas content in coal seam and applied it to the rapid tunneling of coal roadway. Wang [19] studied the law of gas desorption of coal samples through experiments and deduced the calculation formula of gas desorption index of drilling cuttings and residual gas content in coal seam by Langmuir's equation. Gao et al. [20] studied the relationship between gas desorption volume on drilling cuttings and desorption time and analyzed the amount of gas loss when measuring the gas desorption index of drilling cuttings in the field. A quantitative calculation model between residual gas content in coal seam and gas desorption index of drilling cuttings was established. The above domains studied the relationship between the residual gas content in coal seam and the $K_{1}$ value ahead of the roadway advancing face without considering the $S$ value. Some studies have shown that the $S$ value of coal seam containing gas depends on three factors: gas content, in situ stress, and coal mass strength [21-24]. Therefore, both $K_{1}$ and $S$ values can indirectly reflect the residual gas content in the coal seam, which can be used to predict the residual gas content.

In this paper, the outburst risk prediction data of coal roadway advancing face in Yuecheng coal mine were taken as samples, including $K_{1}$ value, $S$ value, and residual gas content. The relationship between $K_{1}$ value, $S$ value (prediction input), and the field measured residual gas content (prediction output) was established by applying the BAELM neural network. The results provide an insight into the relationship between drilling cuttings indices and residual gas content in the coal seam and provided a theoretical guidance for the rapid prediction of residual gas content in front of coal roadway advancing face.

\section{Drilling Cuttings Indices and Residual Gas Content Field Test}

2.1. Principle of Drilling Cuttings Indices Test. Drilling cuttings indices method can quickly determine the risk of gas outburst ahead of coal roadway advancing face by using the parameters $\left(K_{1}, S\right)$. The $K_{1}$ value refers to the gas desorption volume within 1 minute during coal cuttings sheared from the coal mass. Drilling cuttings indices method is adopted to predict outburst in the coal seam. The $K_{1}$ value is measured by WTC outburst parameter instrument every two meters, with the unit of $\mathrm{mL} /\left(\mathrm{g} \cdot \mathrm{min}^{1 / 2}\right)$. The $S$ value refers to the coal cuttings weight per meter during borehole drilling, with the unit of $\mathrm{kg} / \mathrm{m}$.

When the drilling cuttings indices method is used to predict outburst risk in the advancing face in nearly horizontal or gently inclined coal seam, at least 3 predicted boreholes should be drilled. The diameter of these boreholes is $42 \mathrm{~mm}$ and the depth is $8-10 \mathrm{~m}$. The boreholes should be located in the soft stratification of coal seam as far as possible. The directions of the boreholes in the middle of the roadway are consistent with the roadway tunneling. And the end points of boreholes are located in $2-4 \mathrm{~m}$ beyond the two sides of the roadway, as shown in Figure 1.

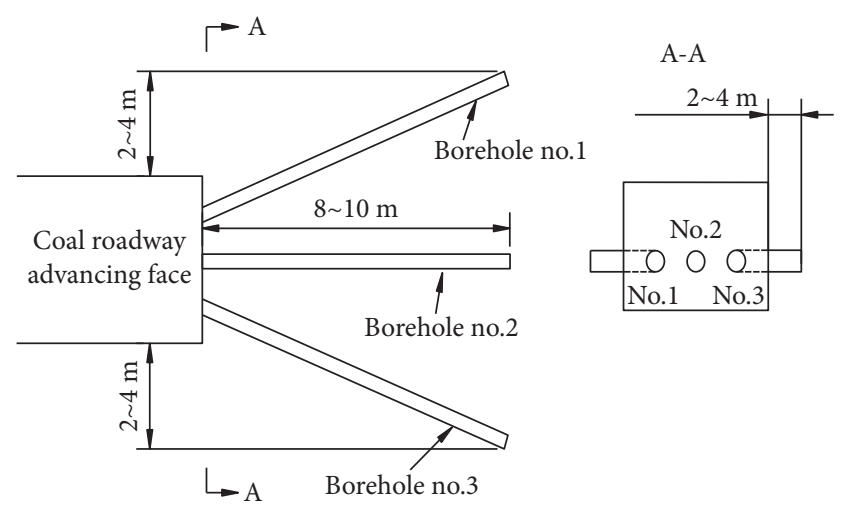

FIgURE 1: Borehole layout for outburst risk prediction in coal roadway advancing face.

2.2. Principle of Gas Content Test. Gas content in coal seam is one of the direct indices to determine the outburst risk in front of advancing face, but it needs a longer testing time compared with the drilling cuttings indices. This index includes nondesorption gas content (normal pressure) and desorption gas content (normal pressure). The nondesorption gas content which is usually a constant for a specific coal seam can be calculated by

$$
Q_{1}=\frac{0.1 a b}{1+0.1 b} \times \frac{100-A_{d}-M_{\mathrm{ad}}}{100} \times \frac{1}{1+0.31 M_{a d}}+\frac{\varphi}{\gamma},
$$

where $Q_{1}$ is the nondesorption gas content at normal pressure $\left(\mathrm{m}^{3} / \mathrm{t}\right), a$ is the gas adsorption constant of coal $\left(\mathrm{m}^{3} / \mathrm{t}\right), b$ is the gas adsorption constant of coal $\left(\mathrm{MPa}^{-1}\right), A_{d}$ is the ash content of coal (\%), $M_{\mathrm{ad}}$ is the moisture content of coal (\%), $\varphi$ is the porosity of coal, and $\gamma$ is the density of coal $\left(\mathrm{t} / \mathrm{m}^{3}\right)$.

The desorption gas content is tested in both underground and surface by direct gas content test device (DGC). The desorption gas content mainly includes three parts: gas loss during underground drilling $\left(Q_{2}\right)$, gas desorption during coal core transport $\left(Q_{3}\right)$, and gas desorption during coal core crushing $\left(Q_{4}\right)$. The test process is shown in Figure 2 [25-27].

The gas content of coal seam is the sum of the nondesorption and desorption gas contents, which can be calculated as follows:

$$
Q=Q_{1}+Q_{2}+Q_{31}+Q_{32}+Q_{4}
$$

where $Q_{31}$ is the gas desorption of coal sample underground $\left(\mathrm{m}^{3} / \mathrm{t}\right)$ and $Q_{32}$ is the surface gas desorption before coal sample crushing $\left(\mathrm{m}^{3} / \mathrm{t}\right)$.

2.3. Results of Drilling Cuttings Indices and Residual Gas Content Tests. In this paper, 95 groups of drilling cuttings indices and residual gas contents in coal seam (the buried depth is $280-530 \mathrm{~m}$, the thickness is $5.04-7.16 \mathrm{~m}$, and the average dip angle is $5^{\circ}$ ) in Yuecheng coal mine were recovered by the drilling cuttings indices method and desorption gas content method during the coal roadway tunneling from June 2018 to December 2018. The above data 


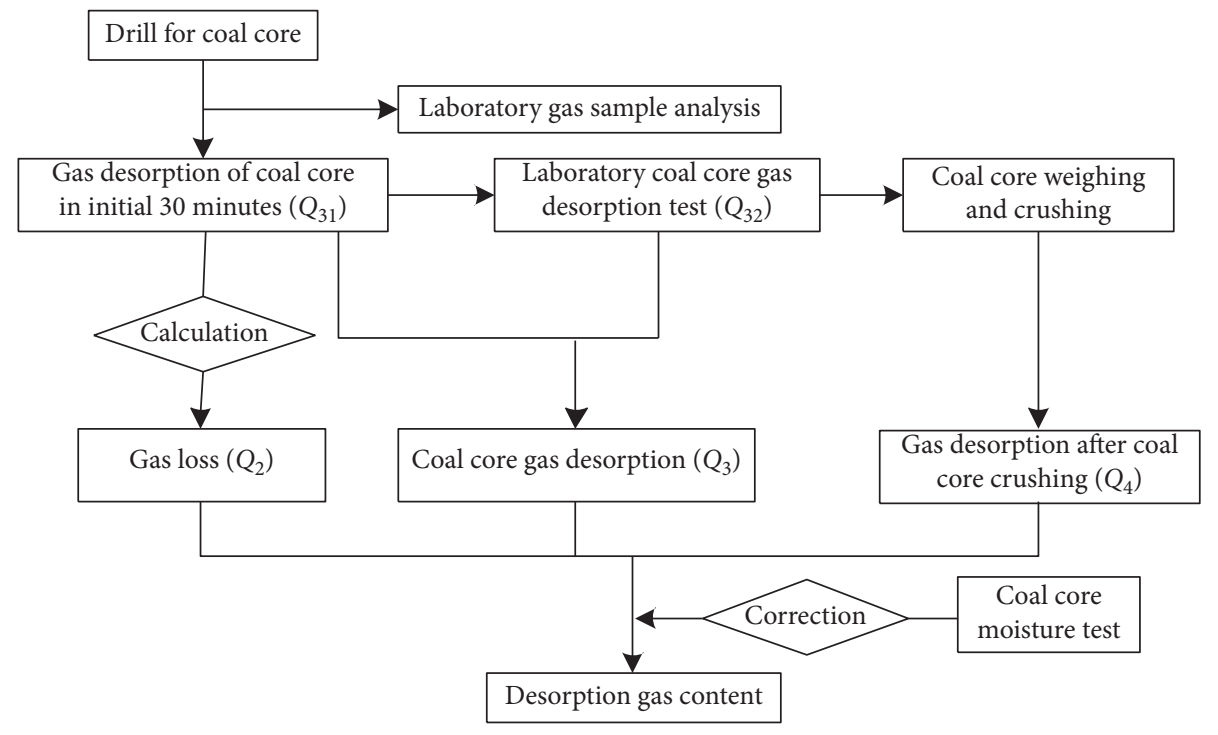

Figure 2: Gas content test process.

were used to verify the outburst prevention measures. In addition, the drilling cuttings indices and the residual gas content in the coal seam were corresponding to each other in the roadway tunneling engineering plan, as shown in Figure 3. Finally, the sample dataset for training and prediction of residual gas content in coal seam was formed, as shown in Table 1.

In the direction of roadway advancing, the drilling cuttings indices were collected per $6 \mathrm{~m}$, and the drilling depth is $10 \mathrm{~m}$. The residual gas content in the coal seam was tested by taking coal core per $30 \mathrm{~m}$, and the drilling depth is $50 \mathrm{~m}$. The drilling cuttings indices and the residual gas content correspond to each other in the end of the tested borehole.

\section{Bat Algorithm Optimizing Extreme Learning Machine Theory}

3.1. Extreme Learning Machine. ELM is a kind of singlehidden-layer algorithms based on feedforward neural network [28-30]. This algorithm can solve the problems of low learning efficiency and complex parameter setting of backpropagation. It is characterized by fast training speed and good generalization performance and can be used to predict residual gas content in coal seam in front of coal roadway advancing face. The algorithm solving process is as follows.

Assume that the sample input matrix is $X$ and the output matrix of the hidden-layer neuron is $H$ :

$$
H=f\left(w X^{T}+b\right)
$$

where $f$ is the activation function, $w$ is the weight between the input layer and the hidden layer, and $b$ is the threshold of hidden-layer neurons.

Assuming the ELM neural network is determined by solving $\beta$, the sample output matrix $Y$ can be expressed as

$$
f\left(w X^{T}+b\right) \beta=Y
$$

where $\beta$ is the weight between the hidden-layer neuron and the output layer.

According to the principle of zero error approximation and least square method, $\beta$ can be calculated as follows:

$$
\min _{\beta}\|H-Y\| \Longrightarrow \widehat{\beta}=H^{+} Y
$$

where $\mathrm{H}^{+}$is the Moore-Penrose generalized inverse of hidden-layer neuron $H$.

3.2. Bat Algorithm Optimizing Extreme Learning Machine. $\mathrm{BA}$ is a mathematical algorithm, which simulates the biological behavior of bats using sonar to detect moving objects and the associated problem of solving optimization objectives [31, 32].

The input weight matrix $w$ and hidden-layer neuron threshold $b$ in ELM model are generated randomly by bat algorithm. When the number of hidden-layer neuron nodes equals zero, some hidden-layer nodes may fail, thus affecting the prediction results. Therefore, BA-ELM was used in this paper to generate the optimal $w$ and $b$. The process of bat algorithm optimizing extreme learning machine neural network is shown in Figure 4 [33-35].

(1) Initialize the bat algorithm parameters: assuming that the individual number of bat population is $N$, the position and velocity of the $q$ th bat are $S_{q}$ and $V_{q}$, respectively, and the emission pulse frequency is $\left[\lambda_{\min }, \lambda_{\max }\right]$, the pulse rate is $r_{0}$, the pulse rate enhancement coefficient is $\gamma$, the loudness attenuation coefficient is $\alpha$, the scope of loudness is $\left[A_{0}\right.$, $\left.A_{\text {min }}\right]$, the number of iterations is $L$, the number of training set samples is $U$, the number of prediction set samples is $V$, and the number of nodes in the ELM model is $P$. Each bat contained optimization parameters $w$ and $b$; the $q$ th bat could be expressed as 


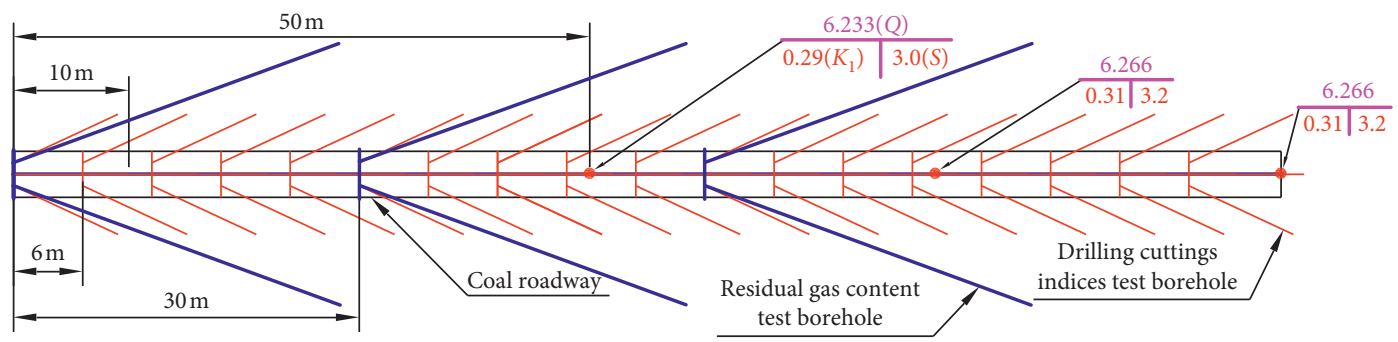

Figure 3: Corresponding diagram of drilling cuttings indices and residual gas content in coal seam.

TABLE 1: Sample dataset for drilling cuttings indices and residual gas content in coal seam.

\begin{tabular}{lccc}
\hline No. & $K_{1}\left(\mathrm{~mL} /\left(\mathrm{g} \cdot \mathrm{min}^{1 / 2}\right)\right)$ & $S(\mathrm{~kg} / \mathrm{m})$ & $Q\left(\mathrm{~m}^{3} / \mathrm{t}\right)$ \\
\hline 1 & 0.29 & 3.0 & 6.233 \\
2 & 0.12 & 2.9 & 5.230 \\
3 & 0.15 & 2.9 & 5.375 \\
4 & 0.16 & 2.9 & 5.417 \\
5 & 0.05 & 3.0 & 4.578 \\
6 & 0.04 & 3.0 & 4.090 \\
7 & 0.03 & 2.8 & 4.020 \\
8 & 0.18 & 2.9 & 5.558 \\
9 & 0.14 & 2.9 & 5.344 \\
10 & 0.18 & 3.2 & 5.611 \\
11 & 0.10 & 3.1 & 5.587 \\
12 & 0.30 & 3.1 & 6.127 \\
13 & 0.13 & 2.9 & 5.397 \\
14 & 0.24 & 3.1 & 5.709 \\
15 & 0.04 & 2.9 & 4.977 \\
16 & 0.08 & 2.8 & 4.755 \\
17 & 0.07 & 3.1 & 5.370 \\
18 & 0.20 & 3.1 & 6.031 \\
19 & 0.25 & 3.7 & 6.510 \\
20 & 0.31 & 3.2 & 6.266 \\
\hline
\end{tabular}

Note. This table lists the first 20 groups of the sample data.

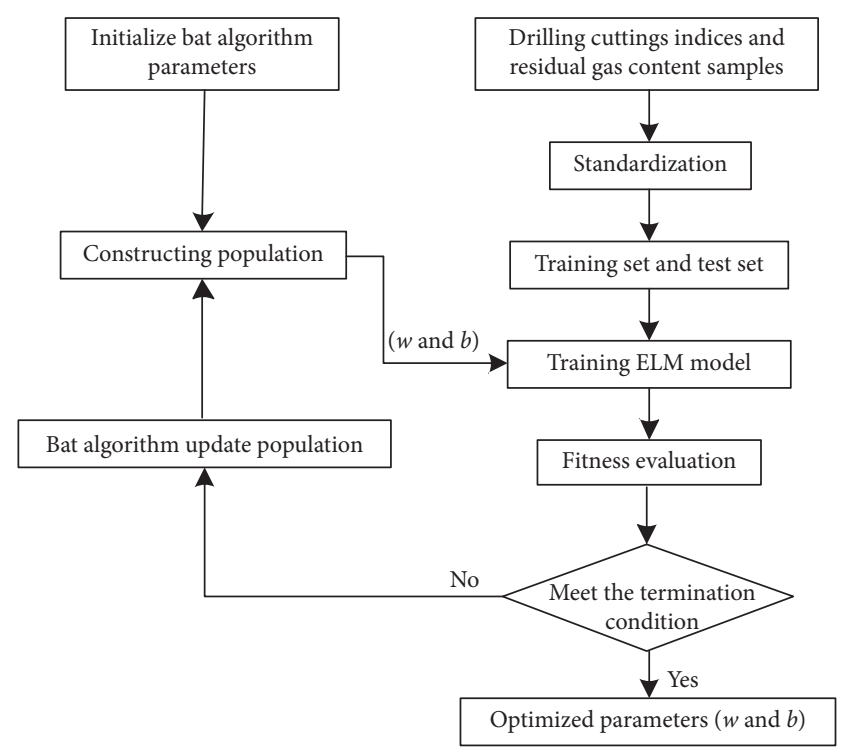

FIGURE 4: Flow chart of BA-ELM method.
$N_{q}=\left[w_{11}, \ldots, w_{1 U}, \ldots, w_{P 1}, \ldots, w_{P U}, b_{1}, b_{2} \ldots, b_{P}\right]$

(2) Assuming that the optimal location of bat population is $S_{N}^{*}$, the fitness function could be expressed by the average square error of the prediction set:

Fit $=\sqrt{\frac{\left(\sum_{j=1}^{V}\left\|\sum_{q=1}^{P} \beta_{q} *\left(w_{q} * S_{j}+b_{q}\right)-t_{q}\right\|_{2}^{2}\right)}{V}}$

where $j=1,2, \ldots, V, V$ is a temporary variable.

(3) Bats detect distances from moving objects by echolocation. After $v$ iterations, the basic parameters of bat $q$ could be updated:

$$
\left\{\begin{array}{l}
\lambda_{q}=\lambda_{\min }+\left(\lambda_{\max }-\lambda_{\min }\right) \sigma \\
V_{q}^{v}=V_{q}^{v-1}+\left(S_{q}^{v}-S^{*}\right) \lambda_{q} \\
S_{q}^{v}=S_{q}^{v-1}+V_{q}^{v}
\end{array}\right.
$$

where $v$ is the current iteration number, and the random variable $\sigma$ ranges from 0 to 1 .

(4) Bat $q$ randomly generated a new location $S_{q M}^{\prime}$ around its selected location. If bat $q^{\prime}$ s fitness $F\left(S_{q M}^{\prime}\right)$ is better than its extreme fitness $F\left(S_{q M}\right)$, the $S_{q M}$ position is updated:

$$
S_{q M}^{\prime}=S_{q M}+\mu A^{v}
$$

where $\mu$ is a random number in the $[-1,1], A^{v}$ is the average of the pulse loudness of all bats at the current iteration number, and ${ }_{M}$ is the dimension of search space.

(5) In the iteration process, if the fitness $F\left(S_{q M}\right)$ of bat $q$ is superior to the fitness $F\left(S^{*}\right)$ of optimal bat $S^{*}$, the basic parameters of bat $q$ should be updated:

$$
\left\{\begin{array}{l}
S^{*}=S_{q M} \\
A_{q}^{v+1}=\lambda A_{q}^{v} \\
r_{q}^{v+1}=r_{q}^{0}[1-\exp (\gamma v)]
\end{array}\right.
$$


(6) If the iteration results satisfied the search termination conditions, the optimal solution was $S^{*}$, the corresponding fitness function was $F\left(S^{*}\right)$, and the corresponding parameters $w$ and $b$ were the optimal parameter values. Otherwise, go back to step (3) and continue iterating through the search until the termination condition was met.

\section{Prediction of Residual Gas Content in Coal Seam Based on BA-ELM}

4.1. Sample Data Standardization. Due to the diversity of magnitude and dimension of $K_{1}$ and $S$ values, the influence of them on residual gas content in coal seam is different. It is necessary to standardize the collected $K_{1}$ value, $S$ value, and residual gas content in the coal seam. The range of collected parameters after standardization is $[-1,1]$, as shown in Table 2.

\subsection{Prediction of Residual Gas Content in Coal Seam Based on} $B A-E L M$. Suppose that the number of bat population $N=200$, initial pulse rate $r_{0}=0.1$, pulse rate enhancement coefficient gamma $\gamma=0.9$, pulse emission frequency $\lambda \in[0,2]$, loudness attenuation coefficient $\alpha=0.9$, loudness range $A \in$ $[1,2]$, and iteration number $L=200$.

The first 80 groups of sample data were used to train ELM neural network. By comparing the operation performance of the neural network with different types of activation function and different number of hidden-layer neurons, the appropriate type of activation function and number of hidden-layer nodes were determined. According to the empirical formula [36], the number of hidden-layer neuron nodes in ELM model was set as 3 (sum of input layer and output layer nodes), and the sigmoidal, sin, and hardlim functions were selected as the activation functions. The generalization performances-average absolute error and training time [37] - of different activation functions were compared, as shown in Table 3.

Prediction results show that the sigmoidal function has the smallest average absolute error under the same condition, and the performance of the model is the best. After the sigmoidal function is selected as the activation function of the model, the reasonable number of hidden-layer neuron nodes is determined by comparing the average absolute error. When the number of hidden-layer neuron nodes is 6 , the average absolute error is the minimum, as shown in Figure 5. Therefore, sigmoidal function is selected as the activation function of ELM neural network, and the number of hidden-layer neuron nodes is 6 .

The last 15 groups of sample data were selected as prediction set, and the corresponding $K_{1}$ and $S$ values were taken as model inputs. The optimized BA-ELM neural network model was used to predict residual gas content. Under the same training and testing sets, the prediction results of BA-ELM method and BP, SVM, and ELM methods on residual gas content were compared to verify the accuracy of the improved method (BA-ELM) $[38,39]$. The prediction results of different models are shown in Figure 6.
TABLE 2: Standardized collected parameters.

\begin{tabular}{lccc}
\hline No. & $K_{1}$ & $S$ & $Q$ \\
\hline 1 & 0.857 & -0.556 & 0.778 \\
2 & -0.357 & -0.778 & -0.028 \\
3 & -0.143 & -0.778 & 0.089 \\
4 & -0.071 & -0.778 & 0.122 \\
5 & -0.857 & -0.556 & -0.552 \\
6 & -0.929 & -0.556 & -0.944 \\
7 & -1.000 & -1.000 & -1.000 \\
8 & 0.071 & -0.778 & 0.236 \\
9 & -0.214 & -0.778 & 0.064 \\
10 & 0.071 & -0.111 & 0.278 \\
11 & -0.500 & -0.333 & 0.259 \\
12 & 0.929 & -0.333 & 0.693 \\
13 & -0.286 & -0.778 & 0.106 \\
14 & 0.500 & -0.333 & 0.357 \\
15 & -0.929 & -0.778 & -0.231 \\
16 & -0.643 & -1.000 & -0.410 \\
17 & -0.714 & -0.333 & 0.085 \\
18 & 0.214 & -0.333 & 0.616 \\
19 & 0.571 & 1.000 & 1.000 \\
20 & 1.000 & -0.111 & 0.804 \\
\hline
\end{tabular}

From Table 4, the generalization performance of BP and SVM prediction models is poor with large errors. The average absolute errors of BP and SVM prediction method are 0.044 and 0.019 higher than ELM prediction method, respectively, and the average absolute percentage errors are 0.009 and 0.005 higher than ELM prediction method, respectively. BA-ELM method optimized by BA algorithm improves the prediction accuracy. Compared with ELM method, the average absolute error and average absolute percentage error of the BA-ELM are decreased by 0.051 and 0.008 , respectively, and the determination coefficient is increased by 0.041 .

According to Figure 7, the minimum absolute error of BA-ELM method for residual gas content in coal seam is -0.16 , while the maximum error is 0.14 . The minimum value of relative error is $0.04 \%$, and the maximum value is $3.03 \%$. The predicted results of coal seam residual gas content by BA-ELM method in this paper have a good agreement with the tested gas content, showing a high prediction accuracy. This model effectively expresses the nonlinear relationship between residual gas content and drilling cutting indices and can be widely used for rapid prediction of residual gas content in coal seam.

\section{Conclusions}

(1) In this paper, an improved method for coal seam residual gas content prediction is proposed on the basis of both drilling cuttings indices and BA-ELM algorithm. The prediction efficiency of residual gas content is elevated by changing the static factors into the dynamic test indices.

(2) The bat algorithm is used to optimize the inherent randomness of the inputs of ELM neural network. The BA-ELM method is applied to the prediction of residual gas content in coal mass ahead of advancing 
TABLE 3: Selection of activation function.

\begin{tabular}{lccc}
\hline Activation function & Hidden-layer node number & Average absolute error & Training time $(\mathrm{s})$ \\
\hline Sigmoidal & 3 & 0.131 & 0.027 \\
Sin & 3 & 0.171 & 0.027 \\
Hardlim & 3 & 0.219 & 0.030 \\
\hline
\end{tabular}

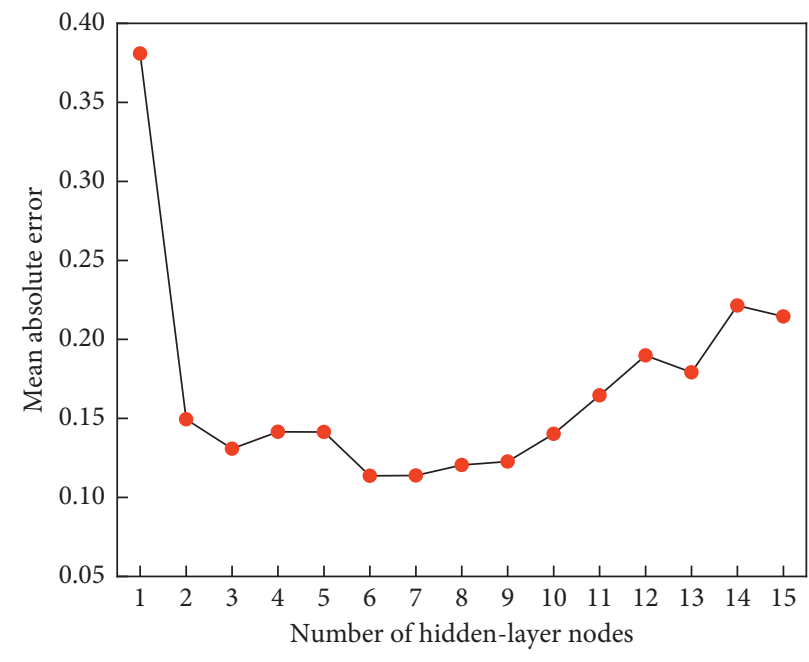

Sigmoidal activation function

FIgURE 5: Selection of hidden-layer nodes.

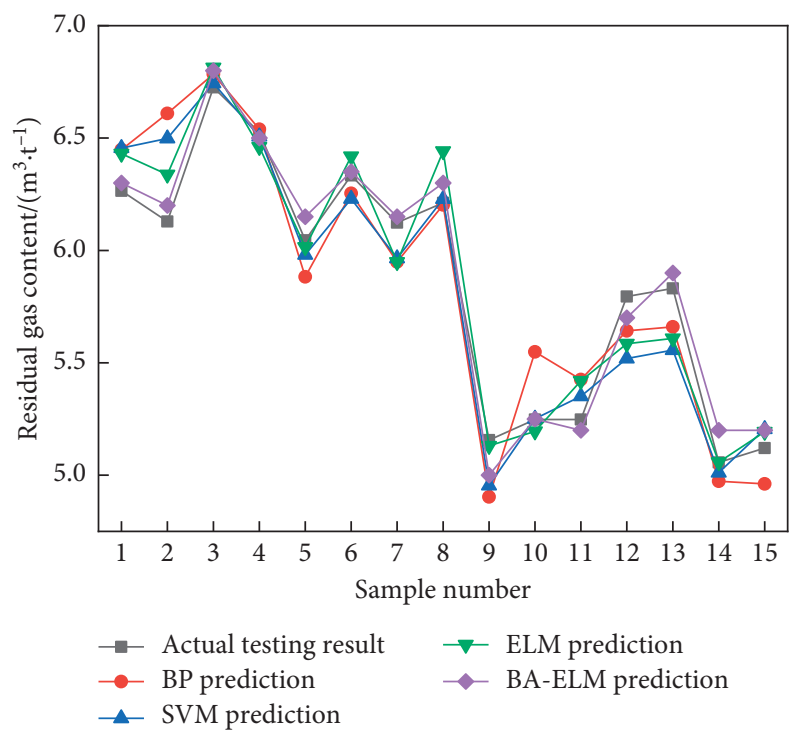

FIgURE 6: Prediction results of different methods.

TABLE 4: Errors and determination coefficients of different prediction methods.

\begin{tabular}{lccc}
\hline Model type & Average absolute error & Average absolute percentage error & Determination coefficient \\
\hline BP & 0.164 & 0.029 & 0.890 \\
SVM & 0.139 & 0.025 & 0.909 \\
ELM & 0.120 & 0.020 & 0.940 \\
BA-ELM & 0.069 & 0.012 & 0.981 \\
\hline
\end{tabular}



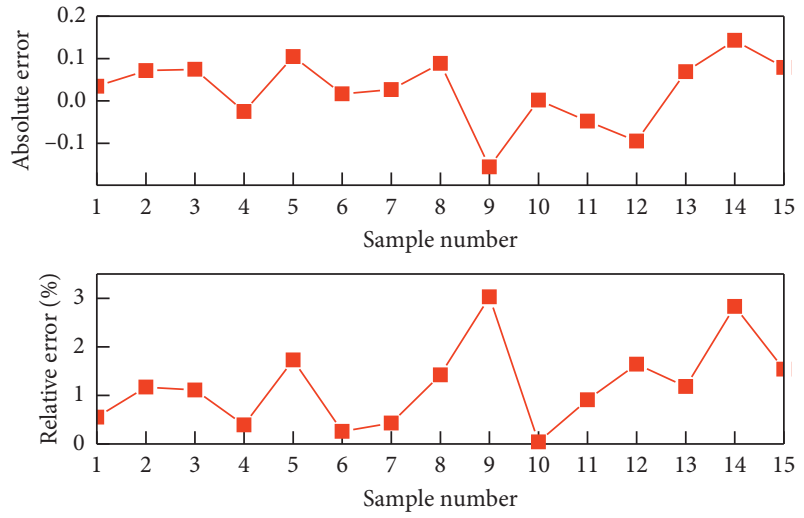

Figure 7: Absolute error and relative error of BA-ELM method.

face. Compared with the tested gas content, the average absolute error is 0.069 , the average absolute percentage error is 0.012 , and the determination coefficient is 0.981 , illustrating an improved prediction accuracy.

(3) Compared with the prediction results of BP, SVM, and ELM methods, the BA-ELM prediction method interprets the nonlinear relationship between residual gas content in coal seam and drilling cuttings indices more accurately and has a wider application prospect in prediction of the residual gas content in coal seam.

(4) In the future study, the mechanical properties of different types of drilling tools [40-44] and their relationship with drilling cuttings indices will be studied. Meanwhile, advanced algorithms such as improved dolphin swarm $[45,46]$ will be applied to further improve the prediction accuracy of residual gas content in coal seam.

\section{Data Availability}

The data used in the article are from the field measurement of a coal mine. Due to the limitation of the length of the paper, the authors cannot present all of them. Therefore, for further details contact Zhenhua Yang via mail (1904835575@qq.com).

\section{Conflicts of Interest}

The authors declare that they have no conflicts of interest regarding the publication of this paper.

\section{Acknowledgments}

This research was financially supported by the National Natural Science Foundation of China (Grants nos. 51674135 and 51674132), Basic Research Project of Key Laboratory of Liaoning Provincial Education Department (Grant no. LJZS004), and Research Fund of State Key Laboratory Cultivation Base for Gas Geology and Gas Control (Henan Polytechnic University) (Grant no. WS2018B05).

\section{References}

[1] C. Fan, S. Li, D. Elsworth, J. Han, and Z. Yang, "Experimental investigation on dynamic strength and energy dissipation characteristics of gas outburst-prone coal," Energy Science \& Engineering, vol. 8, no. 4, pp. 1015-1028, 2019.

[2] B. Huo, X. Jing, C. Fan, and Y. Han, "Numerical investigation of flue gas injection enhanced underground coal seam gas drainage," Energy Science \& Engineering, vol. 7, no. 6, pp. 3204-3219, 2019.

[3] J. Liu, L. Z. Xie, D. Elsworth, and Q. Gan, " $\mathrm{CO}_{2} / \mathrm{CH}_{4}$ Competitive adsorption in shale: implications for enhancement in gas production and reduction in carbon emissions," Environmental Science \& Technology, vol. 53, no. 25, pp. 9328-9336, 2019.

[4] C. Fan, M. Luo, S. Li, H. Zhang, Z. Yang, and Z. Liu, “A thermo-hydro-mechanical-chemical coupling model and its application in acid fracturing enhanced coalbed methane recovery simulation," Energies, vol. 12, no. 4, p. 626, 2019.

[5] C. Fan, S. Li, M. Luo, L. Zhou, H. Zhang, and Z. Yang, "Effects of $\mathrm{N}$ and $\mathrm{S}$ functionalities on binary gas Co-adsorption on a coal macromolecule," Energy \& Fuels, vol. 33, no. 5, pp. 3934-3946, 2019.

[6] Q. T. Hu, Y. L. Zou, G. C. Wen, and X. S. Zhao, "New technology of outburst danger prediction by gas content," Journal of China Coal Society, vol. 32, no. 3, pp. 276-280, 2007.

[7] L. Wang, L.-B. Cheng, Y.-P. Cheng et al., "A new method for accurate and rapid measurement of underground coal seam gas content," Journal of Natural Gas Science and Engineering, vol. 26, pp. 1388-1398, 2015.

[8] S. Xue and L. Yuan, "The use of coal cuttings from underground boreholes to determine gas content of coal with direct desorption method," International Journal of Coal Geology, vol. 174, pp. 1-7, 2017.

[9] L. Qiu, D. Song, Z. Li, B. Liu, and J. Liu, "Research on AE and EMR response law of the driving face passing through the fault," Safety Science, vol. 117, pp. 184-193, 2019.

[10] X. Z. Song, "Storage rule and controlling factors of coalbed gas in Zhaoguan mine field of Huanghebei coalfiled," Coal Geology \& Exploration, vol. 47, no. 1, pp. 73-77, 2019.

[11] J. Lin, T. Ren, Y. Cheng, J. Nemcik, and G. Wang, "Cyclic $\mathrm{N}_{2}$ injection for enhanced coal seam gas recovery: a laboratory study," Energy, vol. 188, p. 116115, 2019.

[12] J. Liu, L. Xie, Y. Yao, Q. Gan, P. Zhao, and L. Du, "Preliminary study of influence factors and estimation model of the enhanced gas recovery stimulated by carbon dioxide utilization in shale," ACS Sustainable Chemistry \& Engineering, vol. 7, no. 24, pp. 20114-20125, 2019.

[13] K. Zhang, Q. Liu, K. Jin, L. Wang, Y. Cheng, and Q. Tu, "Influence of overlying caprock on coalbed methane migration in the xutuan coal mine, Huaibei coalfield, China: a conceptional analysis on caprock sealability," Geofluids, vol. 2019, Article ID 9874168, 17 pages, 2019.

[14] F. Wu, R. B. Gao, Q. L. Zou, J. Chen, W. Liu, and K. Peng, "Long-term strength determination and nonlinear creep damage constitutive model of salt rock based on multistage creep test: implications for underground natural gas storage in salt cavern," Energy Science \& Engineering, 2020, In press.

[15] Q. Zou, H. Liu, Y. Zhang, Q. Li, J. Fu, and Q. Hu, "Rationality evaluation of production deployment of outburst-prone coal mines: a case study of nantong coal mine in Chongqing, China," Safety Science, vol. 122, p. 104515, 2020.

[16] M. G. Xu, S. S. Gao, Y. J. Cao, Y. N. Lu, and J. J. Wang, "Forecast of gas content based on gray theory and multiple 
regression analysis," Safety in Coal Mines, vol. 49, no. 9, pp. 211-214, 2018.

[17] X. L. Zhou, J. Tang, B. M. Shi, and C. Lv, "Analysis and forecast of influential factors of gas content in deep coal seam on the basis of the grey entropy," Coal Geology \& Exploration, vol. 44, no. 2, pp. 19-23, 2016.

[18] S. Zhang, Y. G. Cui, and W. Ren, "Rapid determination method of gas content based on gas desorption law of drilling cuttings," Modern Mining, vol. 8, pp. 215-217, 2016.

[19] Y. J. Wang, "Study on reverse projection of coalbed gas content using desorption of drill cuttings," Coal Technology, vol. 34, no. 12, pp. 153-155, 2015.

[20] X. C. Gao, K. Y. Tian, and P. S. Cen, "Mathematical model of relationship between coal seam gas content $\mathrm{W}$ and gas desorption characteristic index $\mathrm{K}_{1}$ of drill cuttings," Safety in Coal Mines, vol. 42, no. 7, pp. 126-128, 2011.

[21] Z. Zhang, D. Jiang, W. Liu et al., "Study on the mechanism of roof collapse and leakage of horizontal cavern in thinly bedded salt rocks," Environmental Earth Sciences, vol. 78, no. 10, p. 292, 2019.

[22] G. Z. Yin, X. Q. Li, H. B. Zhao, X. S. Li, and G. S. Li, "In-situ experimental study on the relation of drilling cuttings weight to ground pressure and gas pressure," Journal of University of Science and Technology Beijing, vol. 32, no. 1, pp. 1-7, 2010.

[23] J. P. Tang, S. Chen, and N. Yu, "Study on the drilling cuttings bits index of coal and gas outburst based on average effective stress," Progressin Geophysics, vol. 32, no. 1, pp. 395-400, 2017.

[24] L. Qiu, D. Song, X. He et al., "Multifractal of electromagnetic waveform and spectrum about coal rock samples subjected to uniaxial compression," Fractals, 2020, In press.

[25] Chinese Standards, Coalbed Gas content Measurement Methods in Geological Exploration Period, Chinese Standards, Beijing, China, 2009.

[26] W. Liu, Z. X. Zhang, J. Y. Fan, D. Y. Jiang, and J. J. K. Daemen, "Research on the stability and treatments of natural gas storage caverns with different shapes in bedded salt rocks," IEEE Access, vol. 8, pp. 18995-19007, 2020.

[27] H. Li, S. Shi, B. Lin et al., "Effects of microwave-assisted pyrolysis on the microstructure of bituminous coals," Energy, vol. 187, Article ID 115986, 2019.

[28] W. Liu, X. Zhang, J. Fan, Y. Li, and L. Wang, "Evaluation of potential for salt cavern gas storage and integration of brine extraction: cavern utilization, Yangtze River Delta region," Natural Resources Research, 2020, In press.

[29] S. Ding, H. Zhao, Y. Zhang, X. Xu, and R. Nie, "Extreme learning machine: algorithm, theory and applications," Artificial Intelligence Review, vol. 44, no. 1, pp. 103-115, 2015.

[30] G.-B. Huang, D. H. Wang, and Y. Lan, "Extreme learning machines: a survey," International Journal of Machine Learning and Cybernetics, vol. 2, no. 2, pp. 107-122, 2011.

[31] A. H. Gandomi, X.-S. Yang, A. H. Alavi, and S. Talatahari, "Bat algorithm for constrained optimization tasks," Neural Computing and Applications, vol. 22, no. 6, pp. 1239-1255, 2013.

[32] X. S. Yang, "Bat algorithm for multi-objective optimisation," International Journal of Bio-Inspired Computation, vol. 3, no. 5, pp. 267-274, 2011.

[33] S. Li and H. Y. Hu, "Risk identification of coal and gas outburst based on KPCA and improved extreme learning machine model," Application Research of Computers, vol. 35, no. 1, pp. 172-176, 2018.

[34] W. Sun and C. Zhang, "A hybrid ba-elm model based on factor analysis and similar-day approach for short-term load forecasting," Energies, vol. 11, no. 5, p. 1282, 2018.
[35] J. Li, W. Xu, J. Zheng, W. Liu, X. Shi, and C. Yang, "Modeling the mining of energy storage salt caverns using a structural dynamic mesh," Energy, vol. 193, p. 116730, 2020.

[36] N. Wanas, G. Auda, M. S. Kamel, and F. Karray, "On the optimal number of hidden nodes in a neural network," IEEE Canadian Conference on Electrical and Computer Engineering, vol. 2, pp. 918-921, 1998.

[37] G. Zhou, H. Moayedi, M. Bahiraei, and Z. Lyu, "Employing artificial bee colony and particle swarm techniques for optimizing a neural network in prediction of heating and cooling loads of residential buildings," Journal of Cleaner Production, vol. 254, Article ID 120082, 2020.

[38] G. Zhou, H. Moayedi, and L. K. Foong, "Teaching-learningbased metaheuristic scheme for modifying neural computing in appraising energy performance of building," Engineering with Computers, 2020, In press.

[39] W. Qiao, W. Tian, Y. Tian, Q. Yang, Y. Wang, and J. Zhang, "The forecasting of PM2.5 using a hybrid model based on wavelet transform and an improved deep learning algorithm," IEEE Access, vol. 7, pp. 142814-142825, 2019.

[40] M. Habibi, R. Hashemi, A. Ghazanfari, R. Naghdabadi, and A. Assempour, "Forming limit diagrams by including the $\mathrm{M}-\mathrm{K}$ model in finite element simulation considering the effect of bending," Proceedings of the Institution of Mechanical Engineers, Part L: Journal of Materials: Design and Applications, vol. 232, no. 8, pp. 625-636, 2018.

[41] M. Habibi, R. Hashemi, M. Fallah Tafti, and A. Assempour, "Experimental investigation of mechanical properties, formability and forming limit diagrams for tailor-welded blanks produced by friction stir welding," Journal of Manufacturing Processes, vol. 31, pp. 310-323, 2018.

[42] M. Habibi, R. Hashemi, E. Sadeghi, A. Fazaeli, A. Ghazanfari, and H. Lashini, "Enhancing the mechanical properties and formability of low carbon steel with dual-phase microstructures," Journal of Materials Engineering and Performance, vol. 25, no. 2, pp. 382-389, 2016.

[43] M. Alipour, M. A. Torabi, M. Sareban et al., "Finite element and experimental method for analyzing the effects of martensite morphologies on the formability of DP Steels," Mechanics Based Design Of Structures and Machines, pp. 1-17, 2019, In press.

[44] A. Ghazanfari, S. S. Soleimani, M. Keshavarzzadeh, M. Habibi, A. Assempuor, and R. Hashemi, "Prediction of FLD for sheet metal by considering through-thickness shear stresses," Mechanics Based Design Of Structures and Machines, 1-18, 2019, In press.

[45] W. Qiao and Z. Yang, "Solving large-scale function optimization problem by using a new metaheuristic algorithm based on quantum dolphin swarm algorithm," IEEE Access, vol. 7, pp. 138972-138989, 2019.

[46] W. Qiao and Z. Yang, "Modified dolphin swarm algorithm based on chaotic maps for solving high-dimensional function optimization problems," IEEE Access, vol. 7, pp. 110472110486, 2019. 